\title{
A INFLUÊNCIA DO ESTADO NEOLIBERAL NO SISTEMA DE SAÚDE BRASILEIRO DIANTE DO CONCEITO AMPLIADO DE SAÚDE
}

\author{
Manoela Magalhães Alves
}

Especialista em Gestão de Recursos Humanos/FGV/RJ

Mestranda em Políticas Sociais/Laboratório de Políticas e Sistemas de Saúde do Norte Fluminense/UENF/RJ manumagalhaes.25@gmail.com

\author{
Aline Teixeira Marques Figueiredo Silva \\ Especialista em Saúde da Família/UERJ/MS \\ Mestranda em Políticas Sociais/Laboratório de Políticas e Sistemas de Saúde do Norte Fluminense/UENF/RJ \\ alinemrqs13@gmail.com
}

\section{RESUMO}

O presente artigo pretende apresentar os efeitos das propostas neoliberais ao Sistema de Saúde Brasileiro, visto que na atualidade os princípios do Sistema Único de Saúde, institucionalizado pela Constituição Federal de 1988 relativos à integralidade e universalidade, estão cada vez mais ameaçados pela lógica de mercado, onde a participação do Estado, como patrocinador da saúde, torna-se distorcida, quando transfere para a sociedade civil a responsabilidade de prover o bem-estar social da população. A efetiva consolidação do Sistema Único de Saúde, configura-se como possibilidade de mudança na forma com que os serviços e práticas de saúde se organizam, redirecionando enfoques e pautando-se em paradigmas voltados para a saúde enquanto expressão de cidadania. Pressupomos um realce crítico na constituição de políticas públicas de saúde geralmente desvinculadas dos princípios e diretrizes que norteiam o Sistema Único de Saúde.

Palavras-chave: Saúde, Direito, Neoliberal.

\begin{abstract}
This work intends to present the effects of the neoliberal proposals to the Brazilian System of Health, because at the present time the beginnings of the Unique System of Health, institutionalized by the Federal Constitution of 1988 relative to the character of the integration and universality, are more and more threatened by the market logic, where the participation of the State, as sponsor of the health, it is distorted, when it transfers for the civil society the responsibility of providing the social well-being of the population. The effective consolidation of the Unique System of Health, is configured as change possibility in the form with that the services and practices of health are.
\end{abstract}

Keywords: Brazilian System of Health, Unique System of Health.

\section{INTRODUÇÃo}

A política pública de saúde brasileira redimensionou o conceito de saúde como direito do cidadão, de acordo com o artigo 196 da lei no8080/90: "A saúde é direito de todos e dever do Estado, garantido mediante politicas sociais e econômicas que visem à redução do risco de doença e de outros agravos e ao acesso universal e igualitário às ações e serviços para sua promoção, proteção e recuperação" (Brasil, 1998), em contrapartida, de acordo com a política neoliberal, foram introduzidos mecanismos que interrompem o processo de construção de uma seguridade social ampla e baseada nos direitos de cidadania através da privatização de bens e serviços públicos, substituição do aparato estatal de assistência à pobreza por organizações não governamentais - ONGs, entre outros processos (Soares, 2001). 
O conceito ampliado de saúde passou a ser compreendido através de uma leitura biopsicossocial significando um avanço no entendimento de que o indivíduo não se limita apenas à dimensão biológica, tampouco a medicina é a única profissão voltada à recuperação e à garantia de saúde da população. Instaurou-se um olhar multidisciplinar para o processo saúde-doença, pressupondo a atuação de vários profissionais na viabilização das políticas de saúde. (Cavalcanti e Zucco, 2006).

Deve-se compreender que os diferentes padrões ou características de saúde-doença que se concretizam no corpo bio-psíquico dos indivíduos, têm sua gênese nas condições materiais da vida cotidiana, ou seja, nos perfis de reprodução social em que se desenvolvem como seres sociais.

\section{O SUS NO CONTEXTO NEOLIBERAL}

Com a conquista da democracia, a sociedade participou ativamente na formulação de proposições políticas para a saúde durante a $8^{\text {a }}$ Conferência Nacional de Saúde, realizada em 1986, cujas recomendações foram incorporadas em grande parte pela Constituição de 1988.

Em 1947 a Organização Mundial de Saúde formulou o conceito de saúde como sendo o estado de mais completo bem-estar físico, mental e social, e de acordo com Fleury (1997), o termo "saúde" nas últimas décadas do século XX, sofreu um processo de rediscussão, sendo baseados até então, em indicativos como simples ausência de doenças.

A implantação do Sistema Unificado e Descentralizado (SUDS) foi uma estratégia utilizada para a implantação do Sistema Único de Saúde (SUS), cujos dispositivos legais foram aprovados em 1990 (lei $\mathrm{n}^{\circ}$ 8.080/90 e 8.142/90), dando seqüência à reforma do sistema e dos serviços de saúde, inspirada nos princípios e diretrizes da integralidade, equidade, descentralização e participação, buscando a ampliação do acesso e qualidade das ações e serviços de saúde (Paim, 2006).

A partir da efetivação do SUS o sistema de saúde no Brasil foi estruturado em três níveis de atenção: - nível primário, composto pelas unidades básicas de saúde (como Postos e Centros de Saúde), oferece serviços externos, ambulatoriais, nas áreas da promoção da saúde (por exemplo, puericultura, vacinação e cuidados de pré-natal) e prevenção e detecção de doenças (por exemplo, a hipertensão, o câncer e a diabete melitus). Nos dias atuais, a atenção primária à saúde é considerada internacionalmente a base para um novo modelo assistencial de sistemas de saúde que tenham em seu centro o usuário-cidadão (Giovanella, 2009).

- nível secundário, concentra-se as maternidades, os pronto-socorros, os hospitais distritais e o que no Brasil se conhece como policlínicas, clínicas, casas de saúde ou centros médicos, em que se contempla um atendimento ambulatorial e de internação, clínico e cirúrgico, restrito, ou não, a uma especialidade (por exemplo, uma clínica de doenças respiratórias ou um centro de urgências pediátricas).

- nível terciário, classifica-se os hospitais gerais, os hospitais de clínicas e os hospitais especializados no tratamento ou estudo de alguma doença. Tem-se utilizado a denominação de "terciário-quaternário" para os serviços mais complexos desse nível (por exemplo, tratamento de câncer).

Os serviços que compõem um sistema de saúde devem ter o seu número determinado pela população a que se destina a cobertura, ser adequadamente distribuídos pela área geográfica onde vive esta população e manter entre si uma relação que garanta um fluxo ágil de encaminhamentos e atendimentos, de modo a serem mais eficazes (ou seja, cumprirem a sua finalidade com o menor custo possível) e eficientes (ou seja, cumprirem a sua finalidade com a máxima qualidade possível), evitando-se duplicação e retardo na aplicação da ação preventiva, terapêutica ou reabilitadora a que se destinam.

O direito à saúde, defendido na Reforma Sanitária traz intrinsecamente em sua constituição, o apoio, a participação e a pressão dos setores populares. Em outras palavras, o direito social de ter garantida a condição de saúde de uma população supõe o próprio movimento dessa população em conseguir o reconhecimento e a efetivação desse direito. (Fleury, 1997)

Apesar dos avanços obtidos com a promulgação do SUS nas esferas das políticas públicas de saúde, vivenciamos na realidade do século XXI um novo projeto político pautado em propostas neoliberais, onde o Estado funciona como um regulador do mercado, podendo ocasionar enormes demandas nas áreas da saúde, educação e segurança pública.

A proposta do Estado neoliberal como estratégia, é encolher-se ao nível mínimo, deixando em mãos privadas, filantrópicas ou voluntárias, às quais faz apelos constantes de "participação" e "parceria", atividades concernentes ao setor social, definidas como funções públicas essenciais. Também por isso essa reforma de Estado tem sido denominada entre nós de neoliberal, como alusão ao Estado liberal clássico do fim do século XIX e da Primeira República, ou República Velha, no início do século XX (Paim, 2006). 
De acordo com Therborn (2008), "o neoliberalismo é uma superestrutura ideológica e política que acompanha uma transformação histórica do capitalismo moderno".

Segundo Laurell (2002), de acordo com a lógica de mercado, o "produto saúde" deveria ser uma necessidade de consumo individual, cuja satisfação seria uma questão de gosto e de estilo, e não só de necessidade. Porém, saúde, que é uma questão de vida individual e coletiva, exige um padrão público e social, isto supõe entendê-la não como um produto a ser consumido, mas, sobretudo, delinear o projeto que se quer como padrão de qualidade de vida de uma sociedade.

Partindo do pressuposto que o desenvolvimento econômico e social de um país está atrelado à execução de políticas públicas consideradas essenciais para uma sociedade, tais como: saúde, educação e habitação; torna-se fundamental a presença do Estado como provedor e condutor dessas áreas.

De acordo com Soares (2008): "os postulados neoliberais na área social são, basicamente os seguintes: o bem-estar social pertence ao âmbito do privado (suas fontes "naturais" são a família, a comunidade e os serviços privados). Dessa forma, o Estado só deve intervir quando surge a necessidade de aliviar a pobreza absoluta e de produzir os serviços que o setor privado não pode ou não quer fazê-lo. Propondo, portanto um Estado de beneficência pública ou assistencialista, no lugar de um Estado de Bem-Estar Social. Os direitos sociais e a obrigação da sociedade de garanti-los por meio da ação estatal, bem como a universalidade, igualdade e gratuidade dos serviços sociais são abolidos no ideário neoliberal."

A noção de prestação pública é decorrente da garantia do direito à cidadania e da idéia de saúde como bem público não comercializável, sendo o Estado à instituição correspondente. Por este motivo, a presença dele na garantia do acesso universal à saúde é fundamental. Dessa forma, embora o campo da Saúde Coletiva tenha proposto e fundamentado mudanças na organização dos serviços de saúde em nome da atenção às necessidades de saúde da população, esses não têm conseguido oferecer resposta a grande parte dessas pessoas, especialmente no que diz respeito ao acesso à saúde.

\section{A NOÇÃO DE CONCEITO AMPLIADO DE SAÚDE FRENTE À LÓGICA NEOLIBERAL}

A partir da $8^{\text {a }}$ Conferência Nacional de Saúde (1986), foi definido o conceito ampliado de saúde como "resultante das condições de alimentação, habitação, educação, renda, meio ambiente, trabalho, transporte, emprego, lazer, liberdade, acesso e posse da terra e acesso a serviços de saúde".

De acordo com Carvalho e Buss (2008), a $8^{a}$ Conferência Nacional de Saúde (1986), foi um movimento que contribuiu decisivamente para a inclusão na Constituição de 1988 do reconhecimento da saúde como um direito de todo cidadão e um dever do Estado. Para a criação do Sistema Único de Saúde, fundado nos princípios de solidariedade e universalidade, o conceito ampliado de saúde instaurado na contemporaneidade do sistema de saúde brasileiro exige que os determinantes sociais estejam inseridos diretamente no processo saúde-doença.

Através deste novo conceito, engendrado de acordo com o Art.3 da lei n ${ }^{\circ} 8080 / 90$ do SUS, passa-se a determinar: "a saúde tem como fatores determinantes e condicionantes, entre outros, a alimentação, a moradia, o saneamento básico, o meio ambiente, o trabalho, a renda, a educação, o transporte, o lazer e o acesso aos bens e serviços essenciais; os niveis de saúde da população expressam a organização social e econômica do País".

De acordo com Escorel (1995), esta nova concepção de saúde como resultante e como condicionante de um conjunto de fatores, transforma a luta pela saúde numa luta global, por transformação social, onde existem outros elementos primordiais como: habitação, educação, renda etc. É comum ouvir na atualidade, que saúde é ausência de doença, pressupondo a intervenção médica no indivíduo no sentido de recuperar sua saúde com o uso de medicação, exames, internação, entre outras prescrições, caracterizando a estrutura da política de saúde centrada na lógica do adoecimento do indivíduo.

Segundo Giglio-Jaquemot (2005), através de uma perspectiva antropológica, sugere que a doença e a saúde têm uma realidade independente de suas definições biomédicas e são objetos de representações e práticas diversas que variam segundo as sociedades e, ainda dentro dessas, segundo os segmentos sociais e culturais que as compõem.

Em Paim (2006), torna-se imprescindível que a sociedade atinja níveis razoáveis de bem-estar para todos, ou nunca será um lugar de boa convivência. A falta de condições de saúde e bem-estar também fragiliza os indivíduos, comprometendo sua participação integral na sociedade. Esses argumentos indicam que as necessidades de saúde não podem ser tratadas como mercadorias, acessíveis a preços diferenciados, conforme a capacidade de pagamento individual, como conseqüência, a saúde não deve ser objeto de lucro. 
O conceito de Sistema de Saúde está atrelado ao conjunto de relações políticas, econômicas e institucionais responsáveis pela condução dos processos referentes à saúde de uma determinada população e que se concretizam em organizações, regras e serviços que visam alcançar resultados condizentes com a concepção de saúde prevalecente na sociedade (Giovanella, 2008).

Mediante a promulgação do Sistema Único de Saúde, a explicação do processo saúde-doença foi superada teoricamente pela concepção da Organização Mundial de Saúde (OMS), ao definir saúde como completo bem-estar físico, mental e social. A compreensão do conceito de saúde a partir de uma leitura biopsicossocial significou um avanço no entendimento de que o indivíduo não se limitava apenas à dimensão biológica, tampouco que a medicina é a única profissão voltada à recuperação e à garantia de saúde da população. Instaurou-se um olhar multidisciplinar para o processo saúde-doença, o que pressupunha a atuação de vários profissionais na viabilização das políticas de saúde.

Sendo assim, compreende-se que a "inter-relação entre saúde e condições de vida, vem desde a origem da Medicina Social. Nos séculos XVIII e XIX já se colocava a questão de que, ao lado dos fatores físicos e biológicos, fatores sociais e econômicos eram importantes na determinação do adoecimento. Ou seja, isso não é novo, onde as condições de vida sobre a saúde ganharam novos contornos, principalmente, a partir dos anos 1970, com a própria declaração de Alma-Ata ${ }^{I}$ que traz elementos importantes e discutem a atenção primária à saúde, e outros fatores indispensáveis ao bem estar dos indivíduos e à equidade em saúde" (Brasil, 2006).

As propostas de atenção à saúde têm convergido para a atenção focal, que às vezes faz-se necessária alimentando o conflito entre a efetivação do direito à saúde e a garantia de um mínimo necessário para a sobrevivência de grupos específicos, respondendo assim, à necessidade de racionalizar custos com políticas sociais, com vistas à diminuição da presença do Estado.

É nesse contexto que o Banco Mundial vem exercendo um papel central na definição da aplicação de recursos em políticas sociais de países de capitalismo periférico, como o Brasil, sugerindo a racionalização de recursos públicos para as políticas sociais (Viana e Baptista in Giovanella, 2008), modelo da opção incondicional dessa lógica, é o encaminhamento do projeto público de atenção à saúde no país - um benefício que o Estado deve promover apenas em certas condições, com foco nos grupos mais vulneráveis, ou seja, os pobres sem condição de comprar nenhum tipo de serviço privado.

Nessa perspectiva, a responsabilização do indivíduo pela sua saúde reduz a pressão exercida sobre o sistema público, a uma "perspectiva da governabilidade neoliberal", ao mesmo tempo em que neutraliza problemas sociais e associam comportamentos saudáveis a valores mercadológicos - mercadorias passíveis de consumo individual (Soares, 2001).

O mesmo autor cita o Brasil como uma "combinação do desmonte de políticas sociais dirigidas aos mais pobres (como a assistência social) com reformas constitucionais que reduziram ou eliminaram direitos constituidos ao longo de décadas e consagrados na constituição de 1988".

Neste contexto, entende-se que o Estado deve ser responsável pela garantia dos diversos serviços que promovem o bem-estar social da população, e que sua ausência está intimamente ligada à falta de acesso a direitos universais, representados pelo acesso ao consumo de bens produzidos nos serviços públicos, precário e limitado.

\section{CONCLUSÃO}

Historicamente o Brasil conseguiu implantar parte da proposta do Sistema Único de Saúde no que tange ao seu caráter universal, público, democrático, equânime, ético e solidário, assumindo um marco conceitual preliminar mediante a recuperação e redefinição das concepções da Medicina Social do século XIX, no que tange ao conceito de saúde ampliada. Nesta nova concepção de saúde como resultante e como condicionante de um conjunto de fatores, transforma-se a luta pela saúde numa luta global, por transformações sociais, onde existem outros elementos primordiais como: habitação, educação, renda e saneamento básico.

\footnotetext{
${ }^{1}$ De acordo com a Declaração de Alma-Ata (1), ações dos diferentes atores internacionais no sentido de diminuir as diferenças no desenvolvimento econômico e social dos países deveriam ser estimuladas para que se atingisse a meta de saúde para todos no ano 2000, reduzindo-se a lacuna existente entre o estado de saúde dos países em desenvolvimento e desenvolvidos. Fonte: Rev Latino-am Enfermagem, 2004.
} 
Denota-se que as conquistas foram primordiais para estruturação do Sistema de Saúde Brasileiro, onde algumas medidas econômicas de ajuste neoliberal, redução do gasto social público, supressão da noção e direitos sociais, por exemplo, (Soares, 2001), vem ocasionando um contra-senso com relação à noção de prestação pública como decorrente da garantia do direito à cidadania e da idéia de saúde como bem público não comercializável, por este motivo, a presença do Estado na garantia do acesso universal à saúde seria fundamental.

De acordo com Castel (2001): “... realmente quando o navio faz água, cada um tem que despejar a água pelo vertedouro. Mas, em meio às incertezas que hoje são muito numerosas, pelo menos uma coisa é clara: ninguém pode substituir o Estado em sua função fundamental que é comandar a manobra e evitar o naufrágio".

\section{Referências Bibliográficas}

BODSTEIN, R. Atenção básica na agenda da saúde. Ciências e saúde coletiva, São Paulo, v. 7, n. 3, 2002. Disponível em: http://www.scielo.br/scielo.php. Acesso em: 25/06/10.

BRASIL. Ministério da Saúde. CNESnet - Secretaria de Atenção a Saúde - DATASUS. Disponível em: $<\mathrm{http} / / / \mathrm{www}$.cnes.datasus.gov.br>. Acesso em: 25/07/10.

BRASIL. Ministério da Saúde. Média e alta complexidade. Brasília, DF, 2003. Disponível em: http://portal.saude.gov.br/portal/sas/mac/area.. Acesso em: 23 /07/ 2010.

CASTEL, R. As metamorfoses da questão social: uma crônica do salário. 3. ed. Petrópolis: Vozes, 2001.

ESCOREL, S. e GIOVANELLA, L., et al. Políticas e Sistemas de Saúde no Brasil. Rio de Janeiro: Fiocruz, 2008.

ESCOREL, S. Reviravolta na saúde: origem e articulação do movimento sanitário. Rio de Janeiro: Fiocruz, 1998.

FLEURY, S. A questão democrática na saúde. In: FLEURY, S. (Org.). Saúde e democracia: a luta do CEBES. São Paulo: Lemos, 1997.

GIGLIO-JACQUEMOT, A. Urgências e Emergências em Saúde: perspectivas de profissionais e usuários. Rio de Janeiro: Editora FIOCRUZ, 2005.

LAURELL, A. C. (Org.). Estado e políticas sociais no neoliberalismo. São Paulo: Cortez, 2002.

PAIM, J. S. Desafios para a saúde coletiva no século XXI. Salvador: EDUFBA, 2006.

SOARES, L.T. Ajuste Neoliberal e Desajuste Social na América Latina. Petropólis, RJ: Vozes, 2001.

REZENDE, I. e CAVALCANTI, L. F. (orgs.). Serviço Social e Políticas Sociais. Rio de Janeiro: Editora UFRJ, 2006. 